[Article forthcoming in Australasian Philosophical Review.

To be published in an issue devoted to new work by Sally Haslanger.

Please cite final version.]

\title{
Embodiment \& Oppression: Reflections on Haslanger
}

\begin{abstract}
Erin Beeghly
"As I understand them, feminist and queer theory consist not only in giving an account of the meaning of lives of women and men in all their relational and sexual diversity...Feminist and queer theories are also projects of social criticism. These are theoretical efforts to identify certain wrongful harms or injustices, locate and explain their sources in institutions, and social relations, and propose directions for institutionally oriented action to change them. The latter set of tasks requires the theorist to have an account not only of individual experience, subjectivity and identity, but also of social structures" (20). On Female Body Experience, Iris Marion Young
\end{abstract}

\section{Introduction}

In On Female Body Experience, Iris Marion Young argues that a central aim of feminist and queer theory is social criticism. The task is to understand oppression and how it functions. Know thy enemy, so as to better resist. Much of Sally Haslanger's work fits Young's description of feminist and queer theory, and her newest article, "Cognition as a Social Skill," is no exception. In it, Haslanger theorizes mechanisms of social oppression. My aim in this essay is to specify what I believe is special and insightful about Haslanger's new work. However, I will also explore what is missing from it, namely, an account of what Young calls "individual [embodied] experience, subjectivity, and identity." This omission constitutes a serious problem and one that has been noticed frequently by philosophers engaged with her recent work. This essay begins to document the problem and why it matters, both for theory (specifically, for the task of theorizing oppression) and practice (specifically, for the task of identifying ameliorative interventions).

2. Haslanger's project: the big picture \& what's new

There is a lot to love about Haslanger's project, so let me start with that. In her work, one finds a unique framework for understanding oppression. In particular, she is interested in "ideological" forms of oppression, i.e., "those that are enacted unthinkingly or even willingly by the subordinated and/or privileged" (2018: 1). On her view, ideological oppression is especially worth theorizing because it is "insidious" and "far more difficult to identify and critique" than "directly coercive" and violent forms of oppression (1).

"Cognition as a Social Skill" begins with a pointed question: how does ideological oppression take root? Her interest, in particular, is the way in which individuals' consciousness and agency are "colonized under conditions of injustice" (FN 2: 1). In previous work, Haslanger notes that humans have "psychological capacities...to be responsive to and learn from each other," and that these have a role to play in maintaining injustice (2017b: 156-7; 2017a: 14). 
However, this new article deepens the investigation. Whereas previously something called mindshaping was a blip on radar, it now takes center stage. follows:

In a 2001 article, Matteo Mameli introduced the term "mind-shaping." He defines it as

A mind-shaping effect is an effect on the development or structure of a mind. My telling you that I've broken your computer causes a mind-shaping effect in you. It makes you angry. My teaching a child how to tie his shoelaces causes a mind-shaping effect on him. It makes him able to tie his shoelaces (2001: 608).

According to this definition, any effect you have on someone else is an instance of the phenomenon. I teach you a fact or a new skill: that's mind shaping. I make you angry or happy or sad. That's also mind shaping.

What Haslanger means by the term is more specific. "Mind shaping" is a handle for a revisionary theory of and approach to the human mind, advocated by philosophers like Victoria McGeer and Tadeusz Wiesław Zawidski. It is also label for a phenomenon central to the their theories.

McGeer and Zawidski's theories are revisionary for the following reason: they reject standard assumptions about human cognition. According to standard views, cognition is conceptualized as "an individually realized epistemic capacity" (McGeer 2015: 263), and cognitive activity is understood on a scientific model. Babies are likened to tiny scientists in cribs, learning by way of hypothesis testing (see Gopnik et al. 2000). Similarly, adult mental life is described as proceeding in mainly predictive and explanatory modes.

Had Haslanger exclusively discussed mindshaping in her article, it would still be worth reading. The mindshaping literature is fascinating, and it has not yet received uptake among feminist philosophers. This is surprising, in a way. Like many feminist philosophers and critical race theorists, advocates of mindshaping argue that human cognition is inherently interpersonal (hence social in nature) and embodied (hence reflects one's social and historical positioning). Advocates of mindshaping also emphasize the kind of looping effects in which theorists of oppression have long been interested (Mameli 2001: 613).

The views of phenomenologists and mindshaping advocates also overlap. Both groups have been avid critics of the view that humans' primary mode of cognition involves explanation and prediction. In How The Body Shapes The Mind, phenomenologist Shaun Gallagher calls attention to "our pragmatic way of 'being in the world"" and argues that,

phenomenology tells us that explanation and prediction are relatively rare modes of understanding others, and that something like evaluative understanding about what someone means or about how I should respond in any particular situation best characterize most of our interactions (2005: 212).

Additionally, phenomenologists have emphasized the value-laden, normative nature of perception and cognition, something that advocates of mindshaping also emphasize. For example, in Visible Identities, Linda Martín Alcoff argues that, "racism is manifest at the level of perception itself" (2006: 184). Her point is not just that racist predictions and explanations affect what we see and don't see. Rather, she suggests that perception involves epistemic practices and bodily habits, which embody a kind of racial etiquette (184-5). Etiquette is, of course, inherently prescriptive. 
These convergences are noteworthy. They suggest that theorists with methodologies and views quite different from Haslanger's are likely to be interested in mindshaping. Advocates of mindshaping provide a new kind of argument for the kind of claims that feminist and antiracist philosophers have traditionally wanted to defend. Mindshaping arguments are new because they are rooted in claims about the evolutionary development of humans (though see footnote 1).

However, before feminists - or anyone, for that matter-can decide whether the mindshaping literature is ultimately useful, more information is required. While the approach sounds plausible enough, its details get controversial fast. According to Zawidzki, every instance of mindshaping has two components: "it aims at something, that is shaping minds" and, second, "it requires representing that which it aims to accomplish, that is, shaping minds in a specific way" (30). Yet, as he notes, one must be careful. An advocate of mindshaping cannot interpret "representing" as something that requires language. Nor can one understand "aiming at" as something an agent does intentionally.

Here is why: mindshaping is supposed to be historically prior to mindreading. That is, when it comes to evolutionary history, humans must have had the capacity to shape others' minds before we had the ability to attribute beliefs or desires or emotions to others, i.e., to read minds. Moreover, mindshaping mechanisms are supposed to explain why human beings have evolved to develop sophisticated language. As a result, the representations involved in mindshaping must be conceptualized non-linguistically. Mindshaping must be able to occur, even if we take no view on what other people think, feel, or perceive and even if we had no language in which to conceptualize what they might think, feel, or perceive.

The alleged priority of mindshaping raises a puzzling question. How can you shape someone's else's mind, and "aim" to do so, without having a view about what that person thinks or even a language in which to think? As Zawidzki notes, this is a hard question. But it must have an answer, if mindshaping is to be a viable model of cognition. Here is the key if he right:

the goals, functions, purposes, or aims that help constitute mindshaping are [and must be] understood teleofunctionally, that is, in terms of what the mechanisms associated with mindshaping were selected for in evolution (31).

Accordingly, he defines mindshaping as follows:

To state the definition formally, mechanism $\mathrm{X}$ mindshapes target $\mathrm{Y}$ to match model $\mathrm{Z}$ in relevant respects $\mathrm{R}, \mathrm{S}, \mathrm{T}$...if and only if (1) effecting such matches is X's "proper function" in Millikan's (1984) sense; (2) X is performing its proper function, that is, causing $\mathrm{Y}$ to match $\mathrm{Z}$ in respect to $\mathrm{R}, \mathrm{S}, \mathrm{T}$... (3) $\mathrm{Y}$ is a mind, understood as a set of behavioral dispositions or the categorical basis for them; (4) X's performance of its proper function is guided by representations of R, S, T...; and (6) Z is or is somehow derived from an agent other than the agent to which $\mathrm{Y}$ belongs (32).

This definition says a lot, and what it communicates to me is this: "CAUTION!" Though mindshaping resonates with claims that I find appealing as a feminist, the required assumptions for endorsing the model are quite heavy. People don't mindshape. Mechanisms do. Some of these mechanisms are sub-personal: they are exclusively "neural" (60). For example, Zawidzki discusses "a series of powerful yet counterintuitive experimental results in social psychology" that suggest, "human beings automatically, unintentionally, and unconsciously match each other's non-functional behaviors" (50). These behaviors include "postures, mannerisms, 
gestures, facial expressions, and accents" (60). Other mechanisms are partially outside the brain and are "distributed across multiple agents, as in pedagogy or guided imitation, where a teacher can help the target match the model" (31). In all such cases, we must say that the mechanisms "have an aim" and "a proper function." Moreover, to get the model going, we must say that the relevant neural or extra-neural mechanisms are guided by "representations" in a very specific teleofunctional sense. Furthermore, one must be willing to endorse an extremely controversial evolutionary story about how, when, and why these mechanisms were selected and the way in which language emerged out of mindshaping.

I am not, in principle, against endorsing controversial claims! My point is this: readers of Haslanger's article deserve to know the philosophical and empirical baggage associated with mindshaping. Since Haslanger cites Zawidzki approvingly and relies on his evolutionary story, she appears to be endorsing the above claims. As readers, we deserve to know whether she thinks that the mindshaping model (for example, as developed by other theorists like Victoria McGeer) requires such claims and why we ought to endorse them. Zawidzki is emphatic. He believes that the mindshaping model does require the above claims. Without an evolutionary story, there is no way to establish the priority of mindreading over mindshaping, or vice versa. "The distinction between mindreading and mindshaping," he writes, "cannot be captured in terms of simple empirical tests...no crucial experiment can vindicate one understanding at the expense of the other" (xii). Both models of social cognition embrace the same empirical results; they just understand their significance differently.

Let me now turn to a related issue. "Cognition as a Social Skill" is not just about mindshaping. Indeed Haslanger is only interested in mindshaping for instrumental reasons and, in particular, because it purports to explain why humans participate so naturally in oppressive patterns of thought and action. "In my paper," Haslanger writes, "I aim to show how social meanings shape thought and action and how this provides us with resources for thinking about ideology and ideology critique" (7). This way of putting her project takes the emphasis off mindshaping and places it on culture. Culture, she explains elsewhere, "is a network of social meanings, tools, scripts, schemas, heuristics, principles, and the like, which we draw on in action, and which gives shape to our practices" (2017b, 155). To better analyze culture's role in the colonization of consciousness, Haslanger deploys a new set of theoretical resources in her article, borrowed from sociologist Pierre Bourdieu and political scientist James Scott.

The article's second novel feature consists in Haslanger's incorporation of these new tools into her theory. In particular, Haslanger adopts the following concepts: doxa, heterodoxy, orthodoxy, and hidden transcripts. Each of these concepts is complicated in its own right, and I will not explain them here. My point for now is only that these are novel additions to her theory, and they bring her account of oppression into deeper conversation with a wider set of literatures in sociology, history, and political science. They also serve to supplement her existing account of the ways in which people absorb — and well as resist_oppressive views and practices.

\section{An aesthetic \& political interlude}

Now that I've sketched what is new and provocative in Haslanger's article, I want to say something about my experience reading it. This article was not an easy read for me. It left me feeling frustrated and rather puzzled.

Mindshaping, doxa, heterodoxy, orthodoxy, and hidden transcripts. Five new and complicated conceptual tools, introduced quickly to a theory that already boasts an impressive 
amount of technical terminology. The article is also peppered with intricate diagrams, including these two:
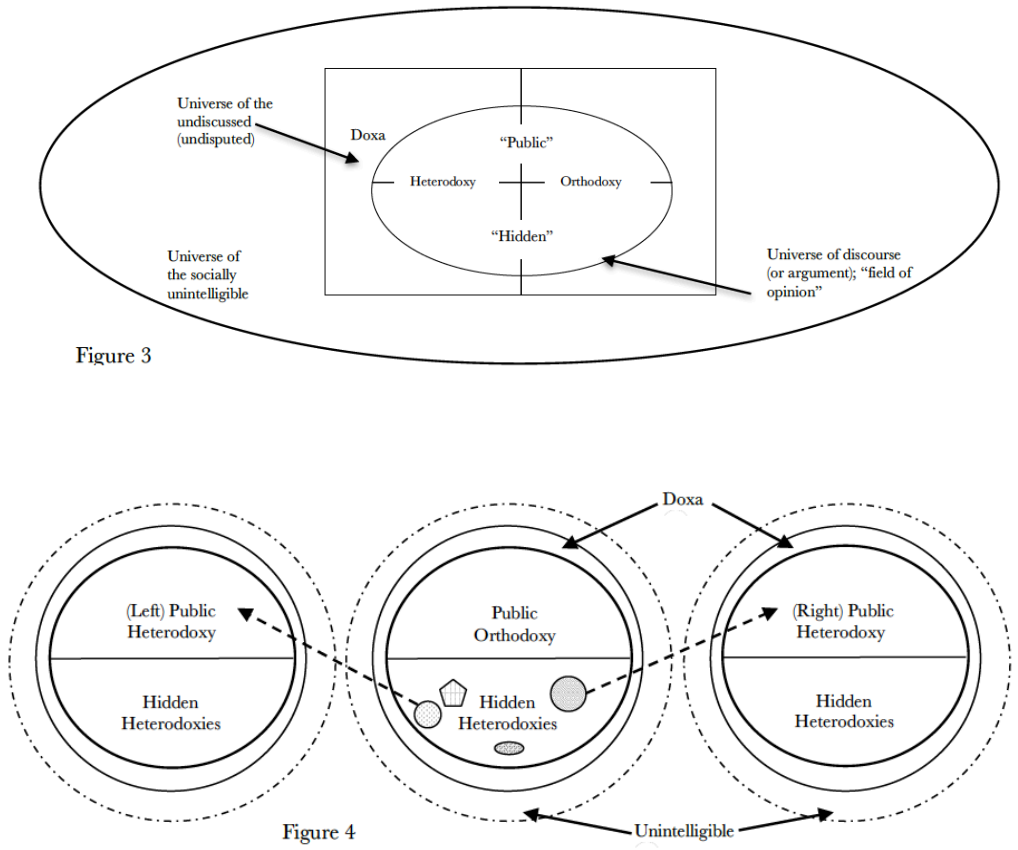

Contemplating these images, my head spins - and not in a good way. Haslanger's theory is already complicated, and these new additions make it even more so. Her implicit promise to readers is this: "Bear with me. The tools of social science can explain ideological oppression" (see Roelofs 2014 for more on the role of promises in aesthetic creations). Yet the analysis often feels byzantine, the payoff elusive. One can't access what interesting about it simply by reading. There is too much jargon, too many moving parts.

Because of this, engaging with Haslanger's new article requires a costly investment. One must sink weeks and weeks, if not longer, into doing the research that illuminates the significance of the various distinctions, concepts, and arguments. These things don't jump off the page and explain themselves. As a reader, I was frustrated at the argument's lack of accessibility and transparency.

As I reflected more, I realized my reaction had feminist roots. Beautiful articles - articles that I aspire to write and read as a feminist philosopher-are not esoteric. They are both intellectually challenging and accessible. Accessibility is a paramount virtue, for which I am willing to sacrifice a lot. When I think of these virtues, I think of theorists like Iris Marion Young and bell hooks. I think, too, of what I call "the bell hooks rule." In her first book ain't $i$ a woman: black women and feminism, hooks writes:

I decided early on that I wanted to create books that could be read and understood across different class boundaries. In those days, feminist thinkers grappled with the question of audience: who we did want to reach with our work? To reach a broader audience required the writing of work that was clear and concise, that could be read by readers who had never attended college or even finished high school. Imagining my mother as my ideal audience - the reader that I most wanted to convert to feminist thinking-I cultivated a 
way of writing that could be understood by readers from diverse class backgrounds (2015/1981: xi).

According to hooks, accessibility and clarity are crucial, both aesthetically and politically. This is also writer Claudia Rankine's position. In a recent interview, Rankine talks about her first book, Don't Let Me Be Lonely, the predecessor of Citizen. She says:

One of the things that I wanted in Don't Let Me Be Lonely was for the language to be transparent. I didn't want people to have to stop and think, I don't know what she means by that. I wanted it to feel simple, accessible, conversational. As a writer, this was the challenge-How do you get the ideas of Butler or Laurent Berlant or Derrida or all the reading you've done, inside the seven sentences that say, I saw this thing and it made me sad? And how do you do it in a way that the research material is not effaced, that trace elements are still present? That seems to me always to be the challenge- to create transparency and access without losing complexity (2016).

One might complain: Rankine writes poetry, not philosophy. Yet, I would argue, philosophers celebrate these same virtues. In "To Do Metaphysics as a Feminist: Reflections on Feminist Methodology in Light of the Hypatia Affair," Ásta notes that what attracted her to analytical philosophy was its emphasis on clarity, as well as its radical potential. "Clarity and precision," she writes, "is a sharp knife for cutting through the obsfucation of demagoguery, ideological manipulation, and plain confusion" (2017: 2).

All of this is to say: I felt, and feel, conflicted about the new article. While it is chock full of interesting concepts and insights, good feminist theory ought to be accessible. Much of Haslanger's other work is. However, this new piece drifts into obscurantism. Obscurity and complexity are not the same thing.

One might object that the subject matter requires a technical treatment and obscurity can be a virtue. An unsympathetic interlocutor might say, "Perhaps you are too simply stupid to understand, Beeghly! Or just plain lazy."

Maybe. But I doubt that. I identify as a pluralist, trained in both the analytic and continental traditions. I am a feminist philosopher. I am not against specialized terminology or theory, and I certainly am not opposed to rolling up my sleeves and digging into an unfamiliar literature. Despite all this, I found the article alienating. Its argument felt cumbersome, the concepts opaque. The mode of address was impersonal. I wanted something more from the article aesthetically, politically, and philosophically.

\section{The problem of embodiment}

As I thought about the accessibility of her new work, it began to dawn on me that there was another, related problem. Often Haslanger uses personal experience as a touchstone for theorizing. For example, in "Race \& Gender: (What) Are They? (What) Do We Want Them to Be?" she begins her analysis by noting "it is always awkward when someone asks me informally what I'm working on and I say that I'm trying to figure out what gender is" (2000: 31). Similarly, in "Changing the Ideology and Culture of Philosophy: Not by Reason (Alone)," she opens with a personal observation about her experience as a female philosopher, announcing: 
there is deep well of range inside me. Rage about how I as an individual have been treated in philosophy; rage about how others I know have been treated; and rage about the conditions that I'm sure affect many women and minorities in philosophy, and have caused many others to leave (2008: 1$)$.

When writing about adoption, family, and race, Haslanger also makes it clear that the subject matter is personal: she is an adoptive parent of two African American children (2005: 265-6; 2009: 7). I love these personal moments. They are powerful and announce to readers the stakes of her philosophical work. However, personal reflections are absent in "Cognition as a Social Skill."

One could argue that the omission is coincidental and that she could add a few vivid examples to make the theory more accessible. But I suspect the fix is not so easy. As far as I can tell, the failure to cite personal experience-hers or anyone else's - in "Cognition as a Social Skill" is a symptom of her methodology.

Consider the framework Haslanger uses to explain ideological oppression — a framework that constitutes one of her philosophical accomplishments and which she has developed carefully over the last decade. She uses the lens of social practices, i.e., "patterns of behavior that enable us to coordinate and distribute resources" (2017b: 3); social structures, i.e., "sets of interconnected practices" (2018: 4); social relations, i.e., "links between nodes in a structure" (2) and ideological formations, i.e., "the practices, institutions, along with the thinking and acting shaped by ideology" (7) which simultaneously justify and help constitute the system as a whole.

Within this conceptual landscape, individuals are understood as "nodes" in social structures. As nodes, they are integral to the system. Yet there is no exploration of the ways in which actual individuals actually experience oppression in a phenomenological, embodied sense. Moreover, actual individuals (like you and me) are irrelevant to the theory; the theory is only interested in individuals qua abstract social types (Haslanger 2016: 121).

Haslanger's view of gender fits nicely with this model. To be a woman, according to Haslanger, is to occupy a particular position in a social structure. She formulates the view as follows:

$\mathrm{S}$ is a woman iff $\mathrm{S}$ is systematically subordinated along some dimension (economic, political, legal, social, etc.) and S is "marked" as a target for this treatment by observed of imagined bodily feature presumed to be evidence of a female's biological role in reproduction (2000: 39).

According to this view, what makes you a woman is not your lived experience or your relationship to gender norms. What makes you a woman is that you are subordinated in particular ways due to your perceived reproductive function.

There is a problem with accounts like this, and it is not about accessibility per se. Haslanger's analysis of oppression, like her view of gender, lacks an account of what Young calls "individual [embodied] experience, subjectivity, and identity" (2007: 20). The omission is not accidental. When Haslanger explains ideological oppression, she intentionally frames her explanations in terms of social structures and the processes by which they are maintained. Such processes can be described without resorting to the nitty-gritty details of any particular individual's psychology, including facts about how it feels for someone to inhabit a certain kind of body. 
Many feminists will object here, and rightly so. Compare Haslanger's view with Iris Marion Young's. Like Haslanger, Young offers a structural analysis of gender. "What it means to say that individual persons are gendered," Young argues, "is that we all find ourselves passively grouped according to these structural relations, in ways too impersonal to ground identity" (22). However, Young does not end her analysis there. Instead she argues that a theory of gender-defined structurally - must be supplemented with an analysis of the lived body (for a feminist critique of the lived body see Leboeuf $\mathrm{ms}$ ).

Young also sinks time and effort into understanding oppression from an embodied perspective. The lived body, she writes, "is a unified idea of a physical body acting and experiencing in a specific sociocultural context; it is a body-in-situation" (16). Drawing on research in the phenomenological tradition, including the work of Simone de Beauvoir and Toril Moi, she fills out the concept of a lived body in a vivid, relatable way. "Each person," Young writes, "is a distinctive body, with specific features, capacities, and desires...is born in a particular place and time, is raised in a particular family setting, and all these have specific sociocultural histories that stand in relation to the history of others in particular ways" (18). Each lived body is therefore unique. On the other hand, individuals face a range of limitations and possibilities that apply across the board to people like them. So there will be commonalities in how people live out their embodiment.

With the concept of the lived body, intentionality and agency rise to the forefront. "The most primordial intentional act," Young writes, "is the motion of the body orienting itself with respect to and moving within its surroundings" (35). We can choose to go this way or that, respond to an obstacle blocking our path in one way or another. Similarly, she argues, individuals have options in how they respond to the "systems of evaluation and expectations" that shape and constrain them (17). "The idea of a lived body," Young explains,

...recognizes that a person's subjectivity is conditioned by sociocultural facts and the behavior and expectations of others in ways that she has not chosen. At the same time, the theory of the lived body says that each person takes up and acts in relation to these unchosen facts in her own way (18).

The interplay of choice and constraint is constant.

Haslanger might interject: I, too, recognize the importance of embodied experience and individual agency! If individuals weren't agents with particular identities and experiences, there would be nothing for culture to colonize. Hidden transcripts and heterodoxy wouldn't be possible if humans had no choice but to conform. Moreover, embodiment is built into my theory of oppression via Bourdieu's notion of a habitus. A habitus consists in a set of bodily dispositions, which enable one to relate to and move through the world in particular ways. She even notes, "social meanings are responsive to our embodied engagement with the world" (2018:7).

Notice the difference, though. While Haslanger's theory of oppression presupposes the existence of embodied experience, she does not engage with embodied experience or individual agency on its own terms. Haslanger offers a top-down structural theory of oppression, supplemented by a discussion of mindshaping. Mindshaping mechanisms are "exclusively neural" or they are "socially distributed" (Zawidzki 2013: 62). First-person experience is not central to the model. Nor does mindshaping give you any handle on how or why individuals could resist oppression and exercise their agency, for example, by creating hidden transcripts. Indeed one of the upshots of mindshaping is that habitual actions and patterns of thought are constitutive of the social structure (see also Zheng 2018). 
The metaphor of colonization - freely invoked by Haslanger-is telling. Colonizers saw colonized peoples as passive and naïve. They sought to control them and appropriate their resources. According to Haslanger, social meanings do the same thing to you and me. Social meanings colonize our consciousness and agency via mindshaping mechanisms. Our inner resources are thus appropriated, taken over. Which is my point. In this picture, individual agency and embodied, first-personal experience are things that have been coopted, usurped vessels used for social-structural purposes. It is thus unclear how humans could ever retain our agency in any meaningful sense and how a critical consciousness could emerge.

One is thus entitled to press Haslanger. How and why is resistance possible, if we accept her theory of oppression? How, exactly, do historically and socially situated individuals and their agency fit into the theory's explanations of how oppression works, both in general and in specific contexts? What is the justification for bracketing first person, embodied experience?

\section{The problem of embodiment: theoretical and practical ramifications}

The fact that I am circling back to these questions is not surprising. They constitute a constant thread in critical appraisals of Haslanger's recent work. Follow the threads with me, by way of conclusion.

Criticism 1-Pigeonholing and Disrespect. One thread of criticism goes as follows. Because Haslanger's theory ignores embodied experience, it ends up pigeonholing individuals in problematic ways.

Though Young could certainly lodge this criticism, one finds it articulated forcefully by other feminists. Katharine Jenkins, for example, argues that Haslanger's account of gender is disrespectful to transwomen (2016: 396). Diagnosing why, she points to the purely structural nature of Haslanger's view. To count as a woman, according to Haslanger, you must be perceived as having a certain kind of body, namely, one capable of fulfilling a female reproductive role. As Jenkins notes, some transwomen will not be subordinated for this reason. They will be subordinated for other reasons. If so, they won't truly be women, according to Haslanger. Jenkins objects: "the concept of being classed as a woman [in the structural sense] and having a female gender identity" should be given equal weight in feminist theory (416). If feminists would give these concepts equal weight, they could craft an analysis of gender suitable for the purposes of feminist liberation. They would be able to see transwomen as bona fide women. Haslanger cannot do this, Jenkins explains, because her analysis prioritizes social structures.

An adjacent criticism concerns Haslanger's account of race. According to Haslanger, to be black is to be oppressed. However, as Janine Jones notes in a review of Resisting Reality, many ordinary black folk understand being black as something to be valued, a source of pride (for a parallel criticism about gender, see Mikkola 2011: 75). Their perspectives are ignored by Haslanger's structural analysis. Jones objects that the methodology fails to recognize something that it absolutely must, namely, "that so many ordinary Black people who theorize their lived experience are experts on race” (2014: 25).

Criticism 2-Explanation \& Agency. Remember, next, that Haslanger characterizes individuals as nodes in a structure. One could perhaps argue that this way of describing human beings is disrespectful because it characterizes individuals as interchangeable, agency-deprived cogs. However, there are explanatory worries in the vicinity as well. 
Consider this one. Theresa Lopez and Bryan Chambliss argue that Haslanger's explanations of individual choice are incomplete (forthcoming). According to Haslanger's theory, individuals act in certain ways because of their location with historically contingent, culturally specific social structures. Yet not all individuals react to the constraints of their social position in the same ways. Two similarly situated people might have radically different relationships to social norms; they may have conflicting values and preferences, as well as divergent attitudes toward risk. If so, structural explanations cannot tell the whole story about individual choice. What we need, Lopez and Chambliss argue, are explanations of choice that appeal both to unique features of individual psychology as well as social structures. They call these integrative explanations of choice.

Critical race theorists often argue for integrative explanations as well. There is a vast, rich literature here. Let me mention two recent examples from sociology. In "Producing Colorblindness: Everyday Mechanisms of White Ignorance," Jennifer Mueller criticizes structural models of colorblindness. She argues that such models "generate explanations that are prone to reify structures while minimizing the agency, creativity, and militancy of whites as a corporate group" (manuscript: 8). Her research shows that white individuals attempt to minimize or deny their complicity in racial injustice in inventive and resourceful ways (2016). Their strategies will not catch your notice if you are looking only at institutions or habitual behaviors. In a recent article, Glenn Bracey and Wendy Moore take a similar tack when explaining why evangelical churches are racially segregated. Noting that structural explanations of dominate the sociological literature, they argue that such explanations hide the ways in which evangelicals in majority-white churches actively exclude potential black congregants. Bracey - a black man with an evangelical history - gathered the data himself. "While we acknowledge the role that macrosocial forces play in maintaining segregation" they write, "we contend that structural relations require institutional dynamics and human actors" (2017: 284).

Though these sociologists do not engage with Haslanger's work specifically, their criticisms apply to her theory. Like Young, they argue that one cannot adequately explain how oppression functions without paying close attention to embodied agents and the ways in which they exert their agency within social structures.

Criticism 3-Embodiment \& Resistance. A final thread of criticism focuses on Haslanger's account of resistance.

Think of Audre Lorde. In "The Uses of the Erotic," she writes that, "the erotic cannot be felt secondhand" (2007/1984: 59). It can only be felt first-hand, from the inside. Explaining what she means, Lorde writes:

As a Black lesbian feminist, I have a particular feeling, knowledge, and understanding for those sisters with whom I have danced hard, played, or even fought. The deep participation has often been the forerunner for joint concerted actions not possible before (59).

As Lorde observes, being together with others in an embodied way-dancing, sweating, arguing - is a source of solidarity. However, this source of solidarity is obscured if we use a methodology that focuses exclusively on structural aspects of social reality, for example, habitual patterns of behavior or thought.

Alex Madva makes a complementary point. In addressing sexism, racism, and other forms of injustice, Haslanger recommends that we focus our activist energy on structural-level 
reforms. Madva thus dubs her a "structural prioritizer" (2016: 703). Structural prioritizers argue that we should reform social structures, and individual-level changes will follow. For example, if we better integrate neighborhoods using public policy, racial prejudices will decrease. Echoing the other critics mentioned so far, Madva takes issue with the strategy: "I believe that it is false and misleading to claim that we should prioritize structural over individual change" (702). We need both kinds of changes to fight oppression; moreover, structural-level interventions must be accompanied by individual-level interventions in order to be maximally stable and effective.

In a similar vein, Robin Zheng criticizes Haslanger's exclusive emphasis on structural reform. "It is all very well to say that we need structural solutions rather than reformed individuals," she writes, "but it is much less obvious what kind of collective action should be taken and how" (Zheng 2018, 6). According to Zheng, justifying collective action to individuals requires convincing them that they should take personal responsibility for unjust social structures. However, questions of personal responsibility are "necessarily addressed from the first- and second-personal practical perspective" (5).

Know thy enemy, so as to better resist. In Madva and Zheng, in Jenkins and Jones, in Lopez and Chambliss, as well as others, one hears the echo of Iris Marion Young. A purely structural theory of oppression, Young argues, cannot explain how oppression gets its hooks in the lived body, as well as the variety of ways in which individuals perpetuate and experience oppression. Nor can it explain how and why resistance is possible. To fully explain oppression and to effectively fight it, a theory must incorporate both social structures and the lived experiences of individuals.

One might object that lived experience resists theory. It is too varied and diffuse and personal. However, I would call attention to the numerous theorists of injustice who theorize from a personal, embodied perspective, while also keeping the structural in view. Think of George Yancy, Lorraine Code, and Franz Fanon. Think of belle hooks and W.E.B. DuBois. ${ }^{1}$ Think of critical race theorists in psychology and sociology (for example, see Salter and Adams 2013; Obasogie 2015). The powerful work of such theorists - and many others - is a testament to the possibility, as well as the desirability, of Young's vision of feminist and queer philosophy as having dual, complementary aims.

"Cognition as a Social Skill" thus returns to a basic problem. Despite its new bells and whistles, the essay is more of the same. Haslanger deploys the third-personal tools of social science - graphs and charts and a focus on abstract structures - to illuminate the phenomenon of ideological oppression. We even get an evolutionary story and new concepts added to the mix. Yet, as far as I can see, the resulting theory only underscores the need, more than ever, to give embodied experience its proper due.

\section{Acknowledgements}

\footnotetext{
${ }^{1}$ It is worth mentioning a related complaint here, namely, that many of the theorists just cited already discuss and document the phenomenon of mindshaping (in McGeer's sense), just not under that name. These theorists go unmentioned in the article. Indeed Haslanger talks about mindshaping as if McGeer and Zawidski invented it. Thanks to Janine Jones for this observation. Jones also argues elsewhere that Haslanger's work would benefit from deeper engagement with historically important antiracist thinkers such as DuBois (Jones 2014, 24-25).
} 
For helpful feedback on this essay, I thank Janine Jones, Alex Madva, Céline, Lebouef, Kathryn Tullman, Brock Bahler, Gabby Yearwood, Dan Kelly, Keota Fields, and Joshua Rivkin. Thank you also to the editors of this issue: Jennifer McKitrick, Mari Mikkola, and Natalie Stoljar. Finally, and most importantly, I thank Sally Haslanger.

\section{Bibliography}

Alcoff, Linda Martín. 2006. Visible Identities: Race, Gender, and the Self. Oxford: Oxford University Press.

Ásta (Sveinsdóttir). 2017. "To Do Metaphysics as a Feminist: Reflections on Feminist Methodology in Light of the Hypatia Affair." Newsletter on Feminism and Philosophy, American Philosophical Association 17: 2-6.

Bracey, Glenn E. and Wendy Leo Moore. 2017. “'Race Tests': Racial Boundary Maintenance in the White Evangelical Church.” Sociological Inquiry 87: 282-302.

Chambliss, Brian and Theresa Lopez. Forthcoming. "Social Structures and Individual Wrongdoing: The Need for An Integrative Account of Social Injustice." Forthcoming

Davidson, Lacey and Dan Kelly. Forthcoming. "Minding the Gap: Bias, Soft Structures, and the Double Life of Social Norms" Journal of Applied Philosophy, Special Issue: Bias in Context.

Gallagher, Shaun. 2005. How the Body Shapes the Mind. Oxford: Oxford University Press.

Gopnik, Alison, Andrew Meltzoff, and Patricia Kuhl. 2000. The Scientist in the Crib: What Early Learning Tells Us About The Mind. New York, NY: William Morrow Paperbacks.

Haslanger, Sally. 2000. "Race \& Gender: (What) Are They? (What) Do We Want Them to Be?" Noûs 34: 31- 55.

. 2005. "You Mixed? Racial Identity Without Racial Biology." Adoption Matters: Philosophical and Feminist Essays. Edited by Sally Haslanger \& Charlotte Witt. Ithaca, NY: Cornell University Press, $265-290$.

. 2008. "Changing the Ideology and Culture of Philosophy: Not by Reason (Alone)" Hypatia 23: $210-233$.

. 2009. "Exploring Race in Life, in Speech, and in Philosophy: Comments on Josh Glasgow's A Theory of Race" Symposia on Gender, Race, and Philosophy 5: 1-9.

. 2015. "Social structure, narrative, and explanation." Canadian Journal of Philosophy 45: 1-15.

$113-130$.

. (2016). "What is a (social) structural explanation?" Philosophical Studies 173: 
. 2017a. "Racism, Ideology, and Social Movements." Res Philosophica 94: 1-

22.

. 2017b. "Culture and Critique." Proceedings of the Aristotlean Society Supplementary Volume 91: xx-xx.

. 2018. "Cognition as a Social Skill.” Australasian Philosophical Review.

. Forthcoming. "What is a Social Practice?" Philosophy.

hooks, bell. 2015/1981. ain't i a woman: black women and feminism. New York: NY: Routledge.

Jenkins, Katharine. 2016. "Amelioration and Inclusion: Gender Identity and the Concept of Woman*" Ethics 126: 394-421.

Jones, Janine. 2013. "Review of Resisting Reality: Social Construction and Social Critique." Newsletter on Philosophy and The Black Experience, American Philosophical Association 13: 19-25.

Leboeuf, Céline. Manuscript. "Bodily Alienation and Feminist Social Critique"

Lorde, Audre. 2007/1984. "The Uses of the Erotic." Sister Outsider: Essays \& Speeches by Audre Lorde. New York, NY: Random House.

Madva, Alex. 2016. “A Plea for Anti-Anti Individualism: How Oversimple Psychology Misleads Social Policy." Ergo 27: 701-728.

Mameli, Matteo. 2001. "Mindreading, Mindshaping, and Evolution." Biology and Philosophy 16: 597-628.

McGeer, Victoria. 2015. "Mind-Making Practices: The Social Infrastructure of Self-knowing Agency and Responsibility." Philosophical Explorations 18: 259-281.

Mikkola, Mari. 2011. "Ontological Commitments, Sex and Gender." In Feminist Metaphysics, ed. Charlotte Witt. New York, NY: Springer: 67-84.

Mueller, Jennifer C. 2017. "Producing Colorblindness: Everyday Mechanisms of White Ignorance," Social Problems 64: 219-238.

. Manuscript. "Rethinking White Colorblindess: Toward a Racial

Ignorance Theory of Knowledge Resistance."

Obasogie, Osagie. 2013. Blinded by Sight: Seeing Race Through The Eyes of the Blind. Palo Alto, CA: Standford Law Books.

Roelofs, Monique. 2014. The Cultural Promise of the Aesthetic. New York, NY: Bloomsbury. 
Rankine, Claudia. 2016. Interview with David Ulin. "Claudia Rankine: The Art of Poetry No. 102." The Paris Review 219: https://www.theparisreview.org/interviews/6905/claudiarankine-the-art-of-poetry-no-102-claudia-rankine

Salter, Phia and Glenn Adams. 2013. "Towards a Critical Race Psychology." Social and Personality Psychology Compass 7/11: 781-793.

Young, Iris Marion. 2007. On Female Body Experience: Throwing Like a Girl \& Other Essays. Oxford: Oxford University Press.

Zawidzki, Tadeusz Wiesław. 2013. Mindshaping: A New Framework for Understanding Human Social Cognition. Cambridge, MA: MIT Press.

Zheng, Robin. 2018. "Bias, Structure, and Injustice: A Reply to Haslanger." Feminist Philosophy Quarterly. 